\title{
Computer use in psychology instruction
}

\author{
MARGARET ANDERSON and PETER HORNBY \\ State University of New York College at Plattsburgh, Plattsburgh, New York
}

\begin{abstract}
This paper presents the ways in which psychology departments are using microcomputers for instruction, the types of facilities that they are using, and the varieties of hardware that they employ. These data are related to other data reported over the past 10 years. In addition, a summary of the types of software currently available in all areas of psychology is presented, and areas in which there is a need for further software development are identified. The information reviewed in this paper was compiled from the current software listings available through COMPSYCH, as well as the results of a survey distributed to registered users of COMPSYCH who hold academic positions.
\end{abstract}

Over the past 10 years, rapid advances in technology have changed the way in which psychologists teach students and conduct research. Particularly significant has been the increasingly widespread use of computers, and most recently the ready availability of microcomputers. During this period, four surveys (Carpenter, 1986; Castellan, 1982; Lehman, 1988; Pavel, 1981) have been conducted in the attempt to identify computer use by psychologists. Although these surveys have differed in orientation, types of individuals surveyed, and specific questions asked, they do have a common goal, and they form a basis of comparison with the material presented here. In addition, tracking these trends over the past 10 years suggests a basis for predicting activity in psychology departments over the next decade.

Just as the increasing presence of microcomputers has changed the nature of instruction within psychology departments, it has also affected the way in which surveys of these changes are conducted. The current ability to establish and maintain data bases, to target survey populations, and to facilitate communication suggests some of the ways in which microcomputers have affected the process of conducting surveys. The use of COMPSYCH (Anderson, Hornby, \& Bozak, 1988; Anderson \& Hornby, 1989) to obtain the data reported in this paper exemplifies the potential of microcomputers for supporting survey research. The data maintained by this system provided the basis of our analysis of current psychology software, as well as the names of the individuals using computers in academic settings who served as our sample.

\footnotetext{
As the present work was being completed, the authors became aware of a new article by Couch and Stoloff (1989), in which they report on data acquired in 1985-1986. They do not seem, however, to have revealed any new trends that might alter the historical perspective developed in the present paper. Requests for reprints should be sent to Margaret Anderson, Department of Psychology, State University of New York College at Plattsburgh, Plattsburgh, NY 12901.
}

\section{COMPSYCH}

COMPSYCH was developed in 1987 by Anderson et al. (1988) to meet the increasing demand for a centralized source of information relating to computer use among psychologists. This computerized system collects and disseminates information about psychology software and its users in all areas of psychology. Since the information available through this system is maintained on a computerized bulletin board, it is immediately accessible to users, registers changes in the status of available software at once, and serves as a means of communication.

COMPSYCH presently provides four major services. It is (1) a catalog of descriptive information about available software, (2) a directory of software users, (3) a message system for sharing information among users, and (4) an announcement service for conferences, workshops, important publications, and other information relating to the use of computers in all areas of psychology. Individuals may access COMPSYCH via modem at (518) 5643372, electronic mail at COMPSYCH@SNYPLAVA, or mail at COMPSYCH, Department of Psychology, SUNY, Plattsburgh, NY 12901.

\section{Survey Goals}

Our primary goal in the present survey was to determine how psychology departments are using microcomputers for instruction. In 1978-1979, Castellan (1982) collected data on the instructional applications of computers in psychology in order to examine demographic information about the responding departments, as well as total instructional computing done on mainframe, mini-, and microcomputers. In 1980, Pavel (1981) sent out questionnaires to 120 individual psychologists to determine their uses of computers in psychology laboratories. Carpenter's 1984 survey (Carpenter, 1986) focused on the use of microcomputers in small psychology departments. These data are particularly interesting, in that the departments were shown to use microcomputers equally in teaching, research, and administration. A 1987 survey by Lehman (1988) of the programming languages that psychologists 
use is also relevant to the present survey, because in it he reports on the specific types of hardware then in use. Although all these surveys have certain common features, they also differ in orientation, often as a result of the currently available technology (both hardware and software). The current survey is focused exclusively on the use of microcomputers on the department level in instructional applications, not on research or administrative uses.

\section{Method}

The survey was mailed to individuals listed on COMPSYCH as computer users who were affiliated with an educational institution. They were asked specifically to report on activity in their entire department, not just their own use of computers in instruction. The survey was mailed out at the end of September 1989, and a response was requested by October 15 . Those surveyed were asked to indicate whether or not they were using microcomputers for instruction in their department. The survey consisted of five questions. Individuals were asked: (1) to list courses in their department in which microcomputers were being used for instruction, (2) to indicate how the microcomputers were being used (a list of six options was provided), (3) to indicate whether they were using in-housedeveloped or commercially available software, (4) to comment on the department facilities in terms of hardware and number of stations available, and (5) to indicate their departments' plans for the future.

\section{Survey Results}

The survey was mailed to individuals at 135 different institutions, 95 in the United States, 18 in Canada, and 22 outside North America. The overall response rate was $53 \%$, with that for the US being $60 \%$; for Canada, it was $55 \%$, and for other countries $22 \%$. The data from these groups have been combined, since the responses did not apparently differ according to geographical location.

Of the individuals who responded, $86 \%$ indicated that their departments used microcomputers in some form of instruction. The $14 \%$ who indicated no instructional use were not asked to indicate the other roles computers played in their departments.

\section{Courses in Which Microcomputers Are Used for Instruction}

On the survey, individuals were first asked to indicate the psychology courses on their campus in which microcomputers were being used for instruction. The responses were categorized according to the courses as the respondents listed them, not according to a set of provided options. The results are presented in Table 1. The data represent the percentage of all respondents who reported using microcomputers in a particular course. For example, $55 \%$ of all who responded indicated that their departments were using microcomputers in statistical instruction. The "other" category includes courses listed by fewer than $5 \%$ of the respondents. These were courses
Table 1

Department Use of Computers in Courses

\begin{tabular}{lc}
\hline \multicolumn{1}{c}{ Course } & Percentage \\
\hline Statistics & 55 \\
Introduction & 34 \\
Experimental & 32 \\
Research methods & 30 \\
Cognitive & 29 \\
Sensation/perception & 19 \\
Physiological & 16 \\
Learning & 15 \\
Computers in psychology & 13 \\
Social & 10 \\
Other & 37 \\
\hline
\end{tabular}

Table 2

Percentage of All Courses in Which Computers Are Used

\begin{tabular}{lcc}
\multicolumn{1}{c}{ Course } & $1978-1979$ & 1989 \\
\hline Statistics & 26 & 19 \\
Research methods & 16 & 22 \\
Introductory & 8 & 12 \\
Social & 3 & 3 \\
Cognitive & 2 & 10 \\
Physiological & 2 & 5 \\
Sensory & 1 & 6 \\
\hline
\end{tabular}

in developmental psychology, artificial intelligence, psychological testing, and so forth.

The results become particularly interesting when they are compared with the data collected by Castellan (1982) in 1978-1979 (see Table 2). The percentage reported indicates the use of microcomputers for instruction in particular courses compared with microcomputer use in all courses. For example, in 1978-1979, 26\% of all courses in which computers were used for instruction were statistics courses, whereas in 1989 , only $19 \%$ of the total use of instructional computing occurred in statistics courses. The only courses recorded are those for which a direct comparison between the two surveys is possible, so the total percentage does not equal 100 . It should also be pointed out that Castellan reported all computer use in teaching psychology courses, whereas the present survey is limited to microcomputer use only. Many who responded to the present survey also indicated that much of their instruction in statistics was still done on a mainframe. It is interesting that statistics and research methods courses continue to account for a majority of computer use in psychology instruction. It is important to note the increase in use of computers for instruction in contentbearing courses. Although Castellan stated in 1982 that "there was no predominant substantive course that made use of instructional computing"' (p. 201), by 1989, 60\% of all courses in which microcomputers were reported as being used for instruction were content-related courses, with introductory and cognitive courses accounting for $12 \%$ and $10 \%$, respectively.

In 1984, Carpenter (1986) found that courses in experimental psychology, statistics, and introductory psy- 
chology together accounted for $64 \%$ of microcomputer use. Experimental psychology, including sensation, perception, cognition, and memory, was the area with the most prevelant use, and it still is, with $32 \%$ of all microcomputer use in the 1989 survey. Carpenter's second most prevalent area included statistics and research methods, which is also true in 1989 , with $30 \%$ of overall use. The area with the third highest use in both surveys comprised general and introductory psychology courses, which accounted for $12 \%$ of microcomputer use in 1989 . Although the similarity in distribution is of interest, it is most important to recognize the increase, by $10 \%$, of the combination of courses indicated.

\section{Computer Use in Instruction}

In the second question, respondents were asked how their departments used microcomputers for instruction; six specific categories were provided. The results of this question are presented in Table 3. These data are particularly interesting when they are compared with Castellan's (1982) results, which indicate that 10 years ago demonstrations enjoyed the most popularity. More recently, Carpenter (1986) found word processing software to be the most popular. In 1989, psychologists are using statistical software most heavily for their instructional needs.

\section{Type of Software Used}

Question three was intended to determine how many departments used their own developed software and how many used software that was commercially developed. The responses indicate that $79 \%$ of the respondents' departments use software that they have developed themselves, and that $90 \%$ use commercially available packages. It is interesting that in $198460 \%$ of the individuals

Table 3

How Computers Are Being Used in Instruction

\begin{tabular}{lc}
\hline \multicolumn{1}{c}{ Use } & $\begin{array}{c}\text { Percentage } \\
\text { of Respondents }\end{array}$ \\
\hline Statistics & 82 \\
Lab component & 77 \\
Research & 76 \\
Word processing & 73 \\
Demonstrations & 65 \\
CAI & 27 \\
\hline
\end{tabular}

Table 4

Type of Hardware in Psychology Laboratories

\begin{tabular}{lcc}
\hline & \multicolumn{2}{c}{ Percentage of Responses } \\
\cline { 2 - 3 } \multicolumn{1}{c}{ Hardware } & Type of Lab & Have in Lab \\
\hline MS-DOS & 49 & 70 \\
Apple II & 14 & 28 \\
Macintosh & 12 & 23 \\
TRS & 2 & 2 \\
Commodore & 2 & 2 \\
MS-DOS/Apple II & 9 & \\
MS-DOS/Mac & 7 & \\
MS-DOS/Apple II/Mac & 5 & \\
\hline
\end{tabular}

responding to Carpenter's survey indicated that they wrote their own software, $27 \%$ of which was for instructional purposes (Carpenter, 1986). It appears that even though commercial software has increasingly become available for psychology instruction, a significant number of departments still feel the need, or simply prefer, to produce their own software to meet instructional needs.

\section{Department Facilities}

The fourth question dealt with the type of computer facilities and hardware that psychology departments were using. Sixty-six percent of the respondents indicated that their department had its own microcomputer facility. The other $34 \%$ did not indicate what type of facilities they were using, but presumably they are central college facilities. The number of stations available in psychology microcomputer laboratories ranges from 3 to 50 , with a mean of 13. This mean may be slightly misleading; the mode was 12 , and $74 \%$ of the departments have fewer than 13 stations available for instruction.

In this question, individuals were also asked to indicate the type of hardware their departments used for instruction. Table 4 summarizes the information thus obtained. These data have been organized in two ways: The first column represents the percentage of departments that have laboratories with a specific hardware configuration, while the second column indicates the percentage of psychology departments that have access to a given type of hardware. These data clearly indicate that a significant majority of psychologists have access to MS-DOS machines for their teaching; the data are particularly impressive from a historical perspective.

Castellan (1982) found that in 1978-1979, 12\% of instructional computing was being conducted on microcomputers. At that time, microcomputers were just becoming readily available. Two years later, Pavel (1981) reported that $36 \%$ of users were employing microcomputers in their psychology laboratories. By 1987, Lehman (1988) found $62 \%$ of all psychologists using microcomputers, $11 \%$ using minicomputers, and $27 \%$ still using mainframes.

Although the surveys conducted over the past 10 years all indicate a significant increase in the use of microcomputers in psychology departments, it is interesting to track the changes in the types of hardware psychologists are using. Data covering a 10-year period are presented in Table 5. It is readily apparent that the popularity of machines using MS-DOS has grown considerably since this operating system's introduction in 1981. At the same time, Apple II (and compatible) machines have declined in popularity. Macintosh use has increased slightly over the past 5 years, while TRS and Commodore use has declined. Particularly interesting is the disappearance of the "other" category. In the early days of microcomputers, a wide range of microcomputers was used. Pavel (1981) found a total of 15 different microcomputers listed in the 49 returns for his survey. The advent of standardized operating systems, commercial software, more departmental laboratories (as opposed to individual machines for per- 
Table 5

Type of Hardware Used in Psychology Departments

\begin{tabular}{|c|c|c|c|c|}
\hline \multirow[b]{2}{*}{ Hardware } & \multicolumn{4}{|c|}{ Percentage of Returns } \\
\hline & $\begin{array}{c}1980 \\
\text { (Pavel, 1981) }\end{array}$ & $\begin{array}{c}1984 \\
\text { (Carpenter, 1986) }\end{array}$ & $\begin{array}{c}1987 \\
\text { (Lehman, 1988) }\end{array}$ & $\begin{array}{c}1989 \\
\text { (current data) }\end{array}$ \\
\hline MS-DOS & & 17 & 41 & 56 \\
\hline Apple II & 37 & 53 & 25 & 22 \\
\hline Macintosh & & & 14 & 18 \\
\hline TRS & 12 & 10 & 2 & 2 \\
\hline Commodore & 12 & & 3 & 2 \\
\hline Other & 40 & 20 & 12 & \\
\hline
\end{tabular}

sonal use), and central funding has led to a move toward the major brands of hardware.

\section{Future Plans}

The final question on the survey concerned departmental plans for the future. A total of 29 individuals indicated that their departments had specific computer-related development plans. Of these, $45 \%$ stated that they would be expanding their software libraries $-24 \%$ that they would be purchasing more commercial packages, and $21 \%$ that they would develop more of their own software. Fifty-five percent of the departments represented in this survey planned to acquire more hardware in the near future. Of these, $10 \%$ intended to purchase Macintoshes, $45 \%$ planned to invest in MS-DOS machines, and none indicated any plans to buy Apple II computers. It appears that departments will continue to expand their use of microcomputers in instruction, with $66 \%$ stating that they would incorporate this technology in more and different courses in the future. Other future plans included networking of laboratory stations, acquisition of overhead projection systems, and the possibility of computerized classrooms.

The trends represented by the preceding analysis of the data collected over the past 10 years are particularly in- teresting when they are combined with an analysis of software currently available to psychologists.

\section{Available Psychology Software}

The following information was compiled from COMPSYCH, which maintains a catalog of software related to all areas of psychology, including instruction, research, and practice. This catalog is organized according to area of specialization, and the data presented here are organized according to these categories. In order for a piece of software to be listed in the COMPSYCH catalog, information must be provided from the original source (developer or distributor). The information listed for each piece of software includes title, authors, address of distributor, date of release, a brief description of the package, intended function (instruction, research, or practice), hardware needed, price, and references to published reviews.

Table 6 summarizes the characteristics of the software currently available. It should be emphasized that this software is primarily designed for psychologists; it does not include any general-purpose software such as word processors, spread sheets, data bases, or test generators. The table shows that there are 480 pieces of software designed for psychological use and that the most software is avail-

Table 6

Analysis of Software Characteristics by Category

\begin{tabular}{|c|c|c|c|c|c|c|c|c|c|}
\hline \multirow[b]{2}{*}{ Software Category } & \multirow{2}{*}{$\begin{array}{l}\text { No. of } \\
\text { Items }\end{array}$} & \multicolumn{3}{|c|}{ Function } & \multicolumn{4}{|c|}{ Hardware Required } & \multirow{2}{*}{$\begin{array}{c}\text { Freeware } \\
(<\$ 5)\end{array}$} \\
\hline & & Research & Instructional & Practice & IBM & Apple II & Mac & Other & \\
\hline General & 22 & & 22 & & 16 & 14 & 2 & 3 & \\
\hline Developmental & 5 & & & 5 & 5 & 4 & & & \\
\hline Physiological & 8 & 1 & 7 & 2 & 1 & 3 & 2 & 3 & \\
\hline Sensation/perception & 13 & 2 & 12 & & 5 & 4 & & 4 & 3 \\
\hline Cognition & 15 & 4 & 13 & 2 & 11 & 7 & & 1 & 1 \\
\hline Learning & 15 & 2 & 13 & 2 & 8 & 8 & & 3 & 1 \\
\hline Industrial/organizational & 6 & & & 6 & 6 & 1 & & & \\
\hline Statistics (tutorial) & 23 & & 23 & & 14 & 10 & 1 & & 1 \\
\hline Statistics (computational) & 56 & 55 & 18 & & 44 & 17 & 3 & 2 & 5 \\
\hline Research methods & 42 & 27 & 35 & & 26 & 20 & 8 & 2 & 3 \\
\hline Social & 14 & 2 & 14 & 2 & 11 & 8 & & & 2 \\
\hline Testing (personality) & 65 & 1 & 1 & 64 & 62 & 40 & 1 & 1 & \\
\hline Testing (intelligence) & 32 & 1 & & 32 & 30 & 29 & 2 & 1 & \\
\hline Testing (vocational) & 11 & & & 11 & 11 & 8 & & & \\
\hline Testing (other) & 13 & 2 & & 11 & 11 & 9 & & 1 & \\
\hline Clinical (diagnostic) & 35 & 2 & 3 & 33 & 33 & 9 & & & \\
\hline Clinical (other) & 48 & & 7 & 40 & 41 & 22 & 0 & 3 & \\
\hline Counselling & 57 & 2 & 3 & 53 & 33 & 40 & 1 & 1 & \\
\hline Total & 480 & 101 & 171 & 263 & 368 & 253 & 20 & 25 & 16 \\
\hline
\end{tabular}


able for personality testing. The most frequently specified use for a piece of software is "practice," which accounts for $49 \%$ of all psychology-oriented software; "instructional" use is second, with $32 \%$ of all software. Of the instructional packages, research methods, statistics, and general psychology have the three largest numbers of packages available, respectively. Although much software is available for more than one type of hardware, $55 \%$ of all software listed with COMPSYCH is designed for MS-DOS machines, 37\% for Apple II computers, less than $4 \%$ for Macintoshes, and another $4 \%$ for "other."

\section{Changes in Available Software}

Every year more (and more varied) software is developed at an increasingly rapid rate. When Butler (1988) discussed the selection of software in the instructional laboratory of 1987, he dealt primarily with generalpurpose software such as that for word processing, graphic displays, electronic mail controllers, and data base managers. He also covered software geared more toward psychology instruction, although still multipurpose, such as data and experiment generators. Essentially he dealt with software as a tool. Today, although general-purpose tools are still abundant, a wide range of software has also been developed for specific instructional purposes.

Table 7 provides a comparison of the software currently available with that listed a year ago. As the table indicates, there has been a $35 \%$ increase in the availability of psychological software in the past year. There has been a $39 \%$ increase for instructional packages. The greatest changes in the availability of software have occurred in the areas of social psychology, physiological psychology, and statistical tutorials, with increases of $64 \%, 62 \%$, and $61 \%$, respectively. When only instructional software is

Table 7 Comparison of Cataloged Software 1988 and 1989

\begin{tabular}{lrrrrr}
\hline & \multicolumn{2}{c}{ Total } & & \multicolumn{2}{c}{ Instruction } \\
\cline { 2 - 3 } \cline { 5 - 6 } \multicolumn{1}{c}{ Software Category } & 1988 & 1989 & & 1988 & 1989 \\
\hline General & 14 & 22 & 14 & 22 \\
Developmental & 5 & 5 & & \\
Physiological & 3 & 8 & 2 & 7 \\
Sensation/perception & 11 & 13 & 11 & 12 \\
Cognition & 7 & 15 & 7 & 13 \\
Learning & 12 & 15 & 10 & 13 \\
Industrial/organizational & 6 & 6 & & \\
Statistics (tutorial) & 9 & 23 & 9 & 23 \\
Statistics (computational) & 28 & 56 & 11 & 18 \\
Research Methods & 28 & 42 & 25 & 35 \\
Social & 5 & 14 & 5 & 14 \\
Testing (personality) & 50 & 65 & & 1 \\
Testing (intelligence) & 17 & 32 & & \\
Testing (vocational) & 10 & 11 & & \\
Testing (other) & 12 & 13 & & \\
Clinical (diagnostic) & 23 & 35 & 3 & 3 \\
Clinical (other) & 31 & 48 & 4 & 7 \\
Counselling & 40 & 57 & 3 & 3 \\
Total & 311 & 480 & 104 & 171 \\
\hline
\end{tabular}

considered, the same three areas lead the way, but their rankings are slightly altered, with physiological psychology listing $71 \%$ new packages, social psychology $64 \%$, and statistical tutorials $61 \%$.

Castellan (1982) identified several areas that appeared to be particularly suitable for software development. The primary areas were statistics and research methods, while the substantive course areas were cognition, sensation, physiological psychology, and social psychology. As Table 7 indicates, these areas are in fact experiencing a major growth in software development. The current listings of available software, especially of software for instruction (Table 7), suggest that there is now considerable room for expansion in the areas of developmental and industrial/organizational psychology.

A comparison of the data presented earlier in Table 1 (department use of computers in courses) with the availability of instructional software presented in Table 7 seems to indicate that there is a strong positive relationship between the types of available software and the courses that rely most heavily on microcomputers for instruction.

\section{Trends for the $90 \mathrm{~s}$}

As we enter the 1990s, it is interesting to speculate on what lies ahead for psychology departments with regard to computer use. Although such predictions are always risky and often remain unfulfilled, they do serve to review current trends and carry them to some logical conclusion. Sometimes predictions regarding the previous decade can actually be reused as predictions of the future. For example, although some of the promises that Castellan (1981) saw in computing for the 1980s have been realized, many can still suggest emerging trends for the 1990s.

The information presented in this paper suggests several future trends: (1) the use of microcomputers will continue to grow rapidly; (2) a wider range of courses will include this medium, and these courses will require more diverse software; (3) although software vendors will continue to offer a substantial proportion of the software, individual development will also continue as more professionals become aware of the power of the microcomputer and more proficient at programming (especially as programming languages become more user-friendly); (4) psychology departments will increasingly have their own departmental laboratories; (5) MS-DOS based machines will continue to enjoy a prominent position in psychology departments, Apple II use will decline drastically, Macintoshes will continue to grow in popularity, and all other microcomputers will disappear from instructional computing; and (6) networking and computerized classrooms (linked to other locations on campuses) will be increasingly available for instruction. During the 1990s, COMPSYCH will continue to track these trends, list software for psychologists, and facilitate communication among psychologists who use computers. 


\section{REFERENCES}

Anderson, M., Hornby, P., \& Bozak, D. (1988). COMPsych: A computerized software information system. Behavior Research Methods, Instruments, \& Computers, 20, 243-245.

ANDERSON, M., HoRNBY, P. (1989). COMPsych. A description and progress report. Behavior Research Methods, Instruments, \& Computers, 21, 205-208.

BUTLER, D. L. (1988). Selection of software in the instructional laboratory. Behavior Research Methods, Instruments, \& Computers, 20 , 175-177.

Carpenter, D. L. (1986). A survey of microcomputer use in small psychology departments. Behavior Research Methods, Instruments, \& Computers, 18, 155-156.
Castellan, N. J., JR. (1981). On-line computers in psychology: The last 10 years, the next 10 years-The challenge and the promise. $B e$ havior Research Methods \& Instrumentation, 13, 91-96.

Castellan, N J., JR. (1982). Computers in psychology: A survey of instrumental applications. Behavior Research Methods \& Instrumentation, 14, 198-202.

Couch, J. V., \& STolofF, M. L. (1989). A national survey of microcomputer use by academic psychologists. Teaching of Psychology, 16, $145-147$

Lehman, R S. (1988) The languages we use. Behavior Research Methods, Instruments, \& Computers, 20, 236-242.

Pavel, M. (1981) Results of a preliminary survey of computer users in psychological laboratories. Behavior Research Methods \& Instrumentation, 13, 272-275. 